\title{
Moral und Fussball, Ethik und Engagement
}

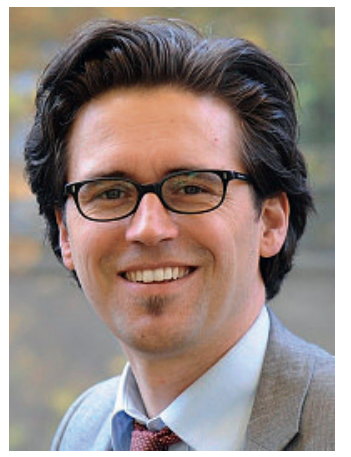

Rouven Porz
«Nach vielen Jahren, in denen mir die Welt viele Erfahrungen bereitet hat, kann ich sagen: Was ich am sichersten über Moral und Verpflichtungen weiss, das verdanke ich dem Fussballspielen.» Albert Camus (1957)

Als ich dieses Zitat zum ersten Mal gelesen habe, da musste ich an meine Jugendjahre beim 1. FC Hilbringen denken (ich spreche von einem kleinen Dorfverein im Saarland, Deutschland). Ich war ein begeisterter Mittelfeldspieler und ich habe seitdem nie mehr so viel über Mannschaftsgeist, Loyalität und Engagement erfahren als in diesen Jahren auf dem staubigen Fussballplatz in Hilbringen. Ich sage bewusst «erfahren» und nicht «erlernt», denn moralische Verpflichtungen kann man kaum theoretisch erlernen, man muss sie in der Praxis «erfahren». Wir alle haben unsere Moralvorstellungen: Werte, Normen, Ziele, Ideen, und ich glaube, meine eigenen haben viel mit Fussball zu tun. Wenn wir ethische Diskussionen führen, dann sollten wir nicht unsere eigenen Moralvorstellungen vergessen, wir mögen aber auch nicht meinen, dass unsere eigene Moral die einzig wahre Ethik wäre. Aber zurück zum Fussball.

\section{«Es darf auch Spass machen»}

Ich möchte mich Ihnen heute als neuer Mitspieler im ethischen Redaktionsteam der SÄZ vorstellen. Gewiss, ich trage eine symbolische Rückennummer auf meinem Trikot, denn ich ersetze den wohlverdienten Stammspieler Christoph Rehmann-Sutter nach dessen Transfer zu einem Club in Lübeck. Die Spielkultur in Deutschland ist anders, die Abseitsfalle oftmals schneller eingerichtet, aber Christoph ist so erfahren in der Champions-League der Ethik, er wird immer das Tor im Auge behalten, da bin ich mir sicher.

Hauptberuflich spiele ich als Ethiker für das Inselspital in Bern, einen traditionsreichen und gleichzeitig zukunftweisenden Club. Mein eigener Transfer nach Bern aus der englischen Stammzellenforschung (Newcastle United) fand letzten Sommer statt. Vorher war ich einige Jahre beim FC Basel tätig. Ich habe mich in Basel in meiner medizinethischen Doktorarbeit mit Genetischen Tests, Absurdität und Grenzsituationen beschäftigt. Auch dabei habe ich mich von Albert Camus inspirieren lassen [1]. Ach so, kurzzeitig war ich auch zu einem mehrmonatigen Gastspiel nach Maastricht ausgeliehen, bei den Holländern konnte ich vor allem meine Techniken in qualitativer Forschung verbessern. In meiner Freizeit spiele ich auch im Vorstand der Schweizerischen Gesellschaft für Biomedizinische Ethik: tolle Themen, tolle Mannschaft, viel Ballgefühl.

Im Inselspital spüre ich wieder einiges von dem Mannschaftsgeist und der Loyalität, die mich zu meiner aktiven Zeit in Hilbringen auch schon so begeistert haben. Als Ethiker in einem Spital ist man natürlich ein Einwechselspieler in heiklen Situationen, gleichzeitig hat man aber auch eine symbolisch wichtige Position im ethischen Strategieaufbau der gesamten Mannschaft. Der Ethiker im Spital ist kein Schiedsrichter und auch kein Trainer. Er (oder sie) «entscheidet» keine Spiele, er «segnet» auch keine schwierigen Spielzüge ab. Der Ethiker spielt Räume frei. Diese Räume können dann zur Reflexion und zum Perspektivenwechsel genutzt werden. Ethik ist eine wissenschaftliche Disziplin des Perspektivenwechsels, eine methodische Reflexion auf Moralvorstellungen. Dazu bedarf es natürlich immer einer gewissen Zeit. Die Ethik versucht also vor allem, die Hektik aus dem Spitalspiel zu nehmen: «Man muss den Ball flach halten, nicht so hoch und hektisch spielen» - wie mein alter Trainer in Hilbringen schon immer gesagt hat.

Natürlich will ich nicht andeuten, dass Ethik ein Spiel wäre oder dass jeder Fussballer auch ein Ethiker sei [2]. Allerdings ist sich jeder Fussballer über Folgendes bewusst: Gespielt wird nach strikten Regeln (deontologisch sozusagen), darüber hinaus muss man die Konsequenzen für die Mannschaft im Kopf behalten (beinahe utilitaristisch). Fussball ist also eigentlich eine Art von indirektem Utilitarismus: transparente Regeln plus transparente Ziele (man verzeihe mir die Vereinfachung). Was aber noch viel wichtiger ist, und hiervon könnten alle Moralapostel, Möchtegern-Ethiker und Miesepeter mal wirklich etwas lernen: Fussball wird mit Leidenschaft, Freude und Engagement gespielt davon würde ich mir ein wenig mehr in der Ethik wünschen. Es darf auch Spass machen.

Rouven Porz*

\section{Literatur}

1 Vgl. Porz R. Zwischen Entscheidung und Entfremdung. Patientenperspektiven in der Gendiagnostik und Albert Camus' Konzepte zum Absurden. Mentis; 2008.

2 Vgl. Porz R. Was die Bioethik vom Fussballspielen lernen könnte. In: Gekauftes Gewissen - Die Rolle der Bioethik in Institutionen. Hrsg. von Porz et al. Mentis; 2007. p. 32-47. 